Special Issue on Longitudinal Methodology, Canadian Studies in Population,

Vol. 28(2), 2001, pp. 249-261

\title{
Using Event-history Analysis: Lessons from Fifteen Years of Practice
}

\section{Céline Le Bourdais}

Centre Interuniversitaire d'études démographiques / Institut national de la recherche scientifique

Montreal, Quebec, Canada

\section{Jean Renaud}

Centre d'études ethniques de l'Université de Montréal

Montreal, Quebec, Canada

\begin{abstract}
:
Innovative statistical methods and new longitudinal surveys paved the way to the widespread use of event-history analysis in social science during the last two decades. This paper does not attempt to provide a comprehensive review of these innovative methods. More modestly, it aims at identifying and describing the problems encountered by two privileged users. Two types of problems are discussed here. The first arises from the design of the surveys, or the way data are collected, and the difficulty to test specific hypotheses with the existing databases; this is the kind of problem that Le Bourdais has faced in analysing family dynamics. The second has to do with the limitations of the survival regression models when the longitudinal phenomena studied can no longer properly be thought of as a small number of unique events; this is the type of problem encountered by Renaud in his ten-year Quebec panel survey of new immigrants.
\end{abstract}


Theoretical Issues - Celine Le Bourdais and Jean Renaud

\section{Résumé:}

Les avancées récentes de la statistique et le développement de nouvelles enquêtes longitudinales ont suscité un engouement pour l'analyse des transitions en sciences sociales au cours des deux dernières décennies. Cet article ne cherche pas à présenter une revue exhaustive des progrès qui ont été réalisés grâce à l'utilisation de cette méthode d'analyse statistique. Plus modestement, il tente d'identifier et de décrire les problèmes rencontrés par deux chercheurs lors de l'application de l'analyse des transitions. Deux types de problèmes sont discutés ici. Le premier est lié à la structure des enquêtes, soit à la nature même des données recueillies, et à la difficulté de tester certaines hypothèses à partir des bases de données existantes; c'est le type de problème rencontré par Le Bourdais dans ses travaux sur la dynamique familiale. Le second tient aux limites des modèles de l'analyse des transitions quand les phénomènes étudiés ne peuvent plus être conceptualisés comme une courte série d'événements uniques; c'est le type de problème auquel a été confronté Renaud au fil de son enquête qui a suivi pendant dix ans une cohorte de nouveaux immigrants.

Key words: Event history analysis, longitudinal surveys in Canada, data for theory, methods for data, l'Etablissement des Nouveuax Immigrants (ENI)

\section{Introduction}

Demographers have long been interested in the study of changes - or transitions - in individuals' lives. The analysis of mortality, nuptiality and fertility, the three main phenomena examined in demography, traditionally consisted of measuring the intensity and timing of transitions from life to death, from celibacy to marriage, and from being childless to having a child. In this type of analysis, each transition is defined by an event that marks the shift from one state to another. It refers to a change in status rather than a change in degree, but a change that is sufficiently clear to be dated quite accurately. Because demographers are interested in estimating not only the cumulative probability that individuals would, for example, eventually marry or die, but also the timing of these events.

To study the intensity and timing of phenomena, demographers turned to the life table method. This method allowed them to take the timing of events into consideration and to take advantage of incomplete histories, i.e. to consider as being at risk all individuals who had not yet experienced the transition and who 
were still at risk of doing so. For a long period, demographers predominantly used census and vital statistics data to study mortality, fertility or nuptiality. These data were usually made available at aggregate levels, and so demographers were able to provide estimates of the intensity and timing of the events analyzed, but not to examine their dynamics at individual level.

In the 1970s, demographic behaviour started changing drastically. Fertility and marriage fell abruptly, separation and divorce increased rapidly while commonlaw unions became more common, first, as a way to start conjugal life and, later on, as the context for family formation. These changes made the use of official statistics less appropriate for the study of conjugal and family life, as the processes of union formation and dissolution increasingly became deinstitutionalized and thus escaped vital statistics registration. Second, they rendered obsolete the use of such concepts as the family life cycle to examine the rising diversity and mobility of individuals' family trajectories, and pointed to the necessity of adopting a life course perspective if the aim is not only to measure but also to explain individual behaviour.

Two important developments, in terms of data and methods, paved the way to the emergence of this type of research. Like many Western countries, Canada started to conduct large retrospective surveys in the 1980s. In 1984, for example, two important surveys - the Family History Survey and the Canadian Fertility Survey - were conducted respectively by Statistics Canada and by the universities of Alberta, Montreal and Western Ontario. These surveys collected detailed retrospective information on the conjugal, parental and employment histories of large samples of respondents, which opened new areas of research in family demography. Three General Social Surveys on the Family were conducted in 1990, 1995 and 2001 (presently under way). In the 1990s, new prospective (panel) longitudinal surveys were introduced. With his "Enquête sur les nouveaux immigrants" that followed, over a ten-year period, a cohort of immigrants who newly arrived in Quebec in 1989, Jean Renaud is one of the pioneers of the design and analysis of prospective longitudinal surveys in Canada. More recently, Statistics Canada has launched a series of new panel surveys, such as the Survey of Labour and Income Dynamics in 1993, the National Longitudinal Survey of Children and Youth in 1994, and the National Population Health Survey in 1994. Additional surveys on youth and on immigrants are also currently under way.

By the mid to the late 1980s, a wealth of data was thus becoming available, allowing researchers to document the life trajectories of individuals (i.e. how events occurred in the course of their life), and to analyse the various factors affecting these trajectories. However, the methodological tools readily accessible to social scientists were still lacking. On the one hand, demographers were well trained in using life table techniques to describe the changing family life course of individuals. But they did not know how to take into consideration the various factors influencing these changes other than by looking at one 
Theoretical Issues - Celine Le Bourdais and Jean Renaud

variable at a time, i.e. by estimating different life tables controlling, for example, for level of education or region of residence. On the other hand, sociologists were familiar with multiple regression analysis. They were good at measuring the net influences of a series of variables or characteristics on a continuous outcome (e.g., the effect of education or experience on income). But, they were generally unaware of the life table method; they did not know how to take timing into consideration and how to handle censored or incomplete histories.

It is in this context that the use of 'event-history analysis' slowly but surely progressed in social science. Often known as 'survival analysis' or 'failure time analysis,' this statistical tool has been used for decades by biostatisticians, interested in modeling the length of life of humans or other living organisms, and by engineers, aiming at predicting the length of time before failure of mechanical components (Luke, 1993). Event-history analysis integrates the life table and multiple regression methods; it takes time into consideration and deals with censored data, and it handles the inclusion of many independent variables into the analysis. Put otherwise, event-history analysis offers a sophisticated way to analyse the net effects of several covariates on the conditional probabilities that individuals experience a given event or transition. A further generalization of Cox's (1972) model (which meant that it no longer required the specification of the variation of the rate of transition through time), combined with the development of new longitudinal surveys, probably explains the rising popularity of event-history analysis within social science disciplines in the last two decades.

This paper does not attempt to provide a comprehensive review of the developments that have been achieved through the use of event-history analysis in the social sciences. It aims only at identifying and describing the problems that we have encountered as privileged users of this method over the last fifteen years. Two types of problems are discussed here. The first arises from the design of the surveys, or from the way data have been collected by Statistics Canada, the principal agency now responsible for conducting large-scale national longitudinal surveys in Canada. This is the kind of problem that Le Bourdais has faced while analysing family dynamics. The second has to do with the limitations of the survival regression models when the longitudinal phenomena studied can no longer properly be thought of as a small number of unique events; this is the type of problem encountered by Renaud in his ten-year Quebec panel survey of new immigrants.

\section{Limits of Existing Surveys: Theory in Search of Data}

In their first research using event-history analysis, Le Bourdais and Desrosiers (1988) used the 1984 Family History Survey to study the dynamics of women's conjugal and employment histories. More specifically, they first described the processes of first union formation and dissolution, distinguishing between 
marriages and common-law unions. Secondly, they carefully documented the rising employment mobility of women, showing that: a) women of younger generations were entering the labour market at a faster pace and in greater proportions than their older counterparts; $b$ ) younger women were leaving their first regular job at much the same rhythm as older generations; but, c) they were re-entering the labour market much faster and in much greater numbers than their predecessors, thus accelerating the pace of movement into and out of employment. The authors moved on to identify the factors that were most likely to influence the probability that women enter or leave a conjugal union, on the one hand, and the probability that they experience transitions in and out of the labour market, on the other. A great deal of effort went into the attempt to model how changing employment status affected conjugal histories and, conversely, to understand how changing family conditions were influencing women's employment trajectories.

In subsequent research, Le Bourdais and her colleagues exploited more fully the richness of the 1984 Family History Survey. By combining the retrospective conjugal and parental histories collected in this survey, they were able to identify the episodes of single parenthood and of family reconstitution that women had experienced prior to the survey. In an article published in 1995, Le Bourdais $e t$ al. analysed the factors related to union formation among single mothers in Canada. This article showed that the propensity of women to move out of single parenthood was closely linked to their evolving employment status and to both the circumstances and the changing historical context in which they experienced this family episode.

The General Social Survey on Family and Friends, conducted in 1990 by Statistics Canada, did not gather any retrospective information on the employment histories of individuals. It did, however, allow us to reconstruct the whole family trajectory that both men and women had followed prior to the survey (Desrosiers et al., 1999) and to analyse the sociodemographic factors that were likely to affect individual family histories, such as the likelihood that women living in a stepfamily separate from their husband or partner (Desrosiers et al., 1995). Unfortunately, the 1990 GSS did not allow us to test further the effect of changing employment conditions on the propensity of both men and women to experience a union or family breakdown. For that, we had to wait for the 1995 GSS on the family that collected information on the employment histories of respondents, in addition to those gathered on conjugal and parental trajectories. The 1995 data allowed us to examine the impact of both the changing patterns of family formation and of female employment on the risk that Canadian women experienced family disruption (Le Bourdais and Neill, 2000). Yet, in spite of its richness, the 1995 GSS on the family has limits that prevent us testing the hypotheses raised by previous studies.

Within the last twenty-five years, both the family and employment episodes have gone through tremendous changes. They have become more unstable, more 
Theoretical Issues - Celine Le Bourdais and Jean Renaud

fluid and harder to define and circumscribe. Family life has become deinstitutionalized and is now easily revocable; employment has become more precarious and a-typical. To what extent are the changes noted in one sphere linked to those observed in the other? Or, put differently, how are conjugal and family dynamics affected by the changing patterns of employment?

Oppenheimer (1993) argued that the delay in marriage observed among the younger cohorts is due to the rising difficulty faced by young men trying to secure a good job. In a fascinating article, Tzeng and Mare (1995) showed that union instability was not mainly associated with female employment, as several studies had previously assumed, but rather to changes experienced through the course of the relationship. Thus, neither the fact that women work nor the number of hours they work at a given moment, in themselves, seem sufficient to account for conjugal instability. However, changes such as increase in the number of hours worked, transition from school to work, or increase in the income of one partner in relation to the other, require adjustments on the part of couples that could lead to separation if not dealt with adequately. These recent studies demonstrate the need to grasp fully the changing patterns of both family and work, and to do so for both conjugal partners, if we are to understand and explain the evolving processes.

Despite impressive progress in data collection, Canada still has some way to go before these kinds of issues can be satisfactorily examined. The National Longitudinal Survey of Children and Youth (NLSCY), which plans to follow until they reach adulthood a large sample of children who were aged 0 to 11 years in 1994-95, contains very detailed data on children's development and well-being, but has little information on parents' socioeconomic trajectories. At the first wave, the NLSCY collected the complete retrospective family histories of both parents (including their on-going parental and conjugal circumstances), but no retrospective data on their employment trajectories. At each wave, the parent questionnaire provides synthesized information on the parent's (more precisely, on the 'person most knowledgeable of the child') employment and income situation in the twelve months prior to the survey and on that of his/her partner. As the survey moves through successive panels, it will allow us to partly explore the extent to which changing patterns of work affect union stability, but only for parents who were together for at least two points of observation.

The Survey of Labour and Income Dynamics follows a very large sample of individuals and households through a six-year period, and provides very refined data to analyze movements into and out of poverty and changes in working conditions. However, information on the past conjugal and family trajectories of individuals is sparse, resulting in left-censored histories (i.e. histories in which the beginning is missing) that are not very useful for the type of analysis we want to conduct. Moreover, the span (6 years) of the follow-up period 
Using Event-history Analysis: Lessons from Fifteen Years of Practice

constitutes too short a period in the life of individuals to allow a comprehensive study of family dynamics.

The General Social Survey on the Family that was launched earlier this year incorporates some useful additions (including a much larger sample size and the collection of retrospective data on educational histories) and innovations (for instance, information on employment trajectories) that will make it even more appealing to researchers. Yet, it presents some major drawbacks that make it impossible to test either Oppenheimer's or Tzeng and Mare's hypotheses. First, it contains almost no retrospective information on the family and work histories of the respondents' partners, thus making it impossible to test how changes couples experience in terms of employment and income affect the stability of their union. Second, the data collected on past regular employment (i.e., full or part-time jobs that lasted at least six months while not studying on a full-time basis) and work interruptions are too broadly defined for insights on the precariousness of the labour market and to adequately test Oppenheimer's hypothesis.

What avenues might be taken to resolve these problems? An upgraded Survey of Labour and Income Dynamics that would collect the complete retrospective histories of individuals prior to the survey and follow individuals for a duration longer than six years would go a long way to filling the gap; a survey, in other words, that would closely resemble the Panel Survey of Income Dynamics that started slightly more than 30 years ago in the U.S.

The longitudinal surveys conducted by Statistics Canada constitute rich databases that make possible numerous types of research. The NLSCY collects rich information to assess the progress and well-being of children at home and at school. Yet, sometimes one has the impression that we forget that children live in families and that their development is influenced by the family and employment trajectories of their parents, trajectories that happen to be quite diversified and unstable and, thus, very difficult to trace. In a way, the difficulties that were discussed above are not confined to the sole study of family and work dynamics. They stem from the fact that the various dimensions of individuals' lives are closely intertwined and cannot be analyzed separately from one another.

\section{Designing a Longitudinal Survey: Data in Search of Methods}

For the last twelve years, Renaud has directed a panel survey studying the integration of new immigrants in Quebec (Renaud et al., 1992, 1993, 2001) called "l'Établissement des Nouveaux Immigrants" (Settlement of New Immigrants) or ÉNI. This survey was designed specifically around the requirements of event history analysis. 
Theoretical Issues - Celine Le Bourdais and Jean Renaud

The study aimed to describe and analyse the processes by which immigrants settle in a new country, in the province of Québec. Immigration is a shared federal-provincial jurisdiction in Canada. For decades, Québec was the only province actively involved in the selection and management of its immigration, largely due to its language specificity in Canada.

The population under study is a cohort of immigrants, 18 years and over, with Québec as their province of destination (on their visa), who arrived in the summer and autumn of 1989 (first use of the visa) and were living in the Montréal area at the end of their first year in Canada. The sample list was established by intercepting these immigrants at the major points of entry in Québec (at the American border and at the airports) and also at the welcome services of the MCCI (Ministère des communautés culturelles et de l'immigration) for those who landed elsewhere in Canada.

The first wave of the panel survey took place during the summer of 1990, with 1000 completed interviews. At that time, the immigrants had been in Canada for an average of 43 weeks. The second wave was conducted one year later and 729 questionnaires were completed. Because of funding problems, the third wave, at the end of their third year in Québec (summer of 1992), was restricted to a random subset of 508 immigrants. Finally, the fourth and last wave was completed by mid-December $1999(n=429)$.

The interviews were conducted face-to-face, using the language chosen by the respondent. To study the integration process, it was important to have information from immigrants who might experience additional difficulties because they did not speak the local languages. Twenty-four languages were used in the first wave of interviews plus many dialectal variations (e.g. four Chinese dialects, three Arabic, etc.). That number fell to twelve in the third wave and to eight in the last wave.

The questionnaire was designed around a calendar that helped respondents remember events and locate them in time, relative to one another. The large paper calendar, with a column for each event and a row for each unit of time, was placed on the table during the interview. Each column, relating to a specific type of event such as employment history, was filled in before moving on to the next. The start and end dates, and the characteristics of each episode were asked. The week was the unit of time used at the first three interviews and the month in the last wave. The calendar was filled up starting with information on lodging, demographics and the most memorable events. Then it proceeded to chains of events whose timing tends to be less easily remembered (jobs first, then courses, then events related to the spouse). These events are usually easier to remember when located relative to the timing of already recorded events. By the end, we had collected the full life history of respondents, starting at migration, with a questionnaire filled in for every spell marked on the calendar: lodging, household composition, paid work, unemployment and education. Migration and 
settling into a new country not being a solitary affair, the immediate household and family context of the respondent was also recorded. Paid work, unemployment and education episodes were recorded for one other member of his or her household, usually the spouse. Part of the first wave questionnaire dealt with pre-migration history. Finally, at every wave, a questionnaire gathered information on variables that changed but that could not be dated, like fluency levels in French or English.

Over the years, the author's attitude towards using event history analysis on this data set evolved from one wave of the survey to the next, and his satisfaction with survival regressions as an analytical tool altered as the time span under observation increased. At the first wave, the data and the model fitted neatly. During the second and third, the data became more cumbersome but were nonetheless manageable. For the most recent wave of the survey, ten years after the immigrants' arrival in Quebec, the methods no longer seem adequate to examine the complexity of the questions raised by the data.

After the first panel, the analysis dealt mostly with 'firsts in Quebec.' access to the first job, duration of the first job, access to language courses, effect of language courses on getting a first job or a first job in French, effect of jobs on getting into a first language course, moving to one's own apartment, giving birth to a first baby in Canada and so on. All those 'firsts' were meaningful, per se. They were the starting points of a new life in a new country. And they had the same meaning for everyone in the sample. Life tables and survival regressions with pre-migration variables and time varying covariates were perfect for the task. In that way, they need no further comment.

But by the second and third waves of observation, every immigrant, in each area of his or her life, was moving on: from one lodging to another, from one job to the next, with or without periods of unemployment in between, from one course to another in the educational system, etc. Life was progressing and the life history questionnaire was recording the progress. But how can one describe and analyse the increasing number of episodes in each area, and how can one relate changes in one chain of events to changes in other chains of events? Without too much of a problem, as it turned out, the span of time under observation was still fairly short (three years) and the first few episodes could provide a good general idea of the underlying dynamic.

Looking globally at a specific chain of events, one can describe the cohort's probability over time of being in a specific state - the probability of being at work for every week in the first three years, for example. While this process does not provide the individual dynamic, it gives us an idea of the cohort's overall dynamic. One can also look at the transitions using Rajulton Fernando's LIFEHIST program to get a general idea of the major sequences of transitions followed by individuals. In the case of jobs (Renaud et al., 1993), for example, one can see that the two most frequent sequences are, first, to get a job and 
remain in it (19\%), and second, the more difficult and unstable sequence of getting a job, becoming unemployed, getting a second job, becoming unemployed again and getting a third job (15\%). And so on. The general description is clear but already the brick wall we were driving towards was looming: with a lot of movement, and a non-markovian process, the nodes get smaller and smaller and the sample would never be large enough to go beyond the fifth transition.

On the regression side, one can use the multivariate version to analyse the first few episodes in the same chain. For example, one can compare the effect of the independent variables on the first three entries into a job or on the duration of these jobs. In the case of language and jobs, this type of analysis clearly shows the changing effect of French language proficiency over time for new immigrants. Immigrants who know French have a shorter duration in their first job and tend to stay much longer in their third job. Language fluency permits mobility at first - quitting the first job more quickly than others - and then stabilizes immigrants in their third job. Again, this kind of analysis is possible because the first few spells (three, in this case) represent the large majority of spells and because the period of time under observation is relatively short. This guarantees a certain homogeneity of meaning for episodes of the same rank. If we were to deal with a much longer period of time, ten years, for example, this would not hold true. A first job starting ten years after migration would not have the same sociological interpretation as a first job starting soon after arrival. Instead of representing the first contact with the society for someone new to it, it would only represent the first contact with its labour market for someone who had already lived ten years in that society. The notion of language knowledge at arrival helping job mobility would be a dubious one for someone entering the labour force after ten years.

More globally, looking at a much longer period with its important increase in the number of episodes forces us to rethink not only about describing and analysing spells but also about the basic notion of 'spell' itself. With only $13 \%$ of immigrants still in their first job after ten years, the study of the first access to the job market or of the duration of the first job, though important to describe the start in a new society, turned out to be just a small piece of a much larger puzzle that includes five or more different jobs, and as many unemployment episodes, for some $15 \%$ of the sample.

There are two ways to get around this new problem. One is to stay within the general framework of life tables and survival regression and to study spells defined not by one single observed episode but by the aggregation of several episodes. For example, single jobs that were the core of the first analyses are now only the building blocks of larger spells defined according to a broader set of properties: how long does one stay in a specific type of industry, in a given socioeconomic status or in a given working language environment? The second solution is to put the notion of transition in the background and to look at the 
Using Event-history Analysis: Lessons from Fifteen Years of Practice

fluctuations over time of the multiple chains of events: this can be thought of as doing time series analysis at the individual level instead of the usual aggregate level. One may, for example, look at the general similarities of career patterns over a ten year period: $30 \%$ of the sample of immigrants tend to get a job quickly upon landing and then stay in the labour market except for minor interruptions, while others have a different history of delayed entry in the labour force or longer interruptions (Renaud et al., 2001: 56-61). In summary, we need to conceptualize the process of insertion into the labour market at a much higher level, i.e. in a more complex but more integrated way, and deal with the current lack of manageable models that are able to keep all the original complexity of the data. With so many events occurring, we have to move to broader analyses and find new ways to correctly model the dynamics of the 'settling-in' process. With ten years of observation, the number of episodes in each sequence has grown so much that it becomes unpractical to do one regression per spell. It would be preferable to relate two or more sequences of events more closely (courses, jobs, and reproductive behaviour, for instance) to get an idea of the general dynamics of how the immigrants settled. After all, in the long run, the real dynamics lies more in the relation between chains of events than in the dynamics of any specific change of state.

\section{Conclusion}

The introduction of event history analysis has permitted social sciences to take more fully into account the complexity of social life. There has been a clear improvement in modelling event dynamics and in understanding the processes under study; it has forced us to go beyond the simple description of change to try to identify the causes of those changes. For demographers and sociologists, it has meant a change in paradigm, modifying the way we collect data, the way we conduct analyses and the way we theorize: the notion of dynamics, the idea of processes, have taken centre-stage.

Fifteen years ago, when the authors started working with event history analysis, there was, so to speak, a magical sparkle about exploring new territories and bringing new life to old fields. Today, the magic has not disappeared even though we have experienced limitations in terms of available data, modelling and revision of concepts. It still has a promising future and we know more clearly now what is needed for its future development. First and foremost, social theory as well as mathematics will have to be at the core. More thinking and more integration are needed. 
Theoretical Issues - Celine Le Bourdais and Jean Renaud

\section{References:}

Cox, D.R. 1972. "Regression models and Life Tables," Journal of the Royal Statistical Society, Series B 34: 187-202.

Desrosiers, H., H. Juby and C. Le Bourdais. 1999. "Female Family Paths" (chapter 3), "Male Family Paths" (chap. 4), in Péron, Y. et al. (dir.), Canadian Families at the Approach of the Year 2000, Ottawa, Statistics Canada,.Pp. 101-153, 155-206.

Desrosiers, H., C. Le Bourdais and B. Laplante. 1995. "Les dissolutions d'union dans les familles recomposées : l'expérience des femmes canadiennes," Recherches sociographiques, XXXVI(1): 47-64.

Le Bourdais, C. and H. Desrosiers. 1988. Trajectoires démographiques et professionnelles : une analyse longitudinale des processus et des déterminants, Montréal, INRS-Urbanisation, rapport soumis au ministère de la Santé et du Bien-être social (Canada) dans le cadre de l'Étude sur l'évolution démographique et son incidence sur la politique économique et sociale.

Le Bourdais, C., H. Desrosiers and B. Laplante. 1995. "Factors Related to Union Formation Among Single Mothers in Canada," Journal of Marriage and the Family 57(2): 410-420.

Le Bourdais, C. and G. Neill. 2000. "Family Disruption in Canada : Impact of the Changing Patterns of Family Formation and of Female Employment," Canadian Studies in Population 27(1): 85-105.

Luke, D. A. 1993. "Charting the Process of Change: A Primer on Survival Analysis," American Journal of Community Psychology, 21 (2): 203-245.

Oppenheimer, V.K. 1993. "Women's Rising Employment and the Future of the Family in Industrial Societies," Population and Development Review 20(2): 293-342.

Renaud J., A. Carpentier, C. Montgomery and G. Ouimet. 1992. La première année d'établissement d'immigrants admis au Québec en 1989. Portraits d'un processus. Ministère des communautés culturelles et de l'immigration, $77 \mathrm{p}$. (see http:/www.ceetum.umontreal.ca/eni/Portrait_T1.pdf) 
Using Event-history Analysis: Lessons from Fifteen Years of Practice

Renaud J., S. Desrosiers and A. Carpentier. 1993. Trois années d'établissement d'immigrants admis au Québec en 1989. Portraits d'un processus, Ministère des communautés culturelles et de l'immigration, coll. Études et recherches, no 5.

(see http:/www.ceetum.umontreal.ca/eni/Portrait_T3.pdf)

Renaud J., L. Gingras, S. Vachon, C. Blaser, J. F. Godin and B. Gagné. 2001. Ils sont maintenant d'ici! Les dix premières années au Québec des immigrants admis en 1989, Les Publications du Québec, MRCI collection Études, recherches et statistiques, numéro 4, Sainte-Foy.

Tzeng, J. and R. Mare. 1995. "Labor Market and Socioeconomic Effects on Marital Stability,” Social Science Research 24(4): 329-351. 